\title{
Heat Treatment to Improve Fatigue Strength of Friction Stir Welded Ti-6Al-4V Alloy Butt Joint
}

\author{
Masaaki Nakai ${ }^{1, * 1}$, Mitsuo Niinomi ${ }^{2,3,4,5}$, Yu Ishida $^{2, * 2}$, Huihong Liu ${ }^{6}$, Hidetoshi Fujii ${ }^{6}$ \\ and Takashi Ninomiya ${ }^{7}$
}

${ }^{1}$ Faculty of Science and Engineering, Kindai University, Higashiosaka 577-8502, Japan

${ }^{2}$ Institute for Materials Research, Tohoku University, Sendai 980-8577, Japan

${ }^{3}$ Graduate School of Engineering, Osaka University, Osaka 565-0871, Japan

${ }^{4}$ Graduate School of Science and Technology, Meijyo University, Nagoya 468-8502, Japan

${ }^{5}$ Institute of Materials and Systems for Sustainability, Nagoya University, Nagoya 464-8603, Japan

${ }^{6}$ Joining and Welding Research Institute, Osaka University, Ibaraki 567-0047, Japan

${ }^{7}$ Aerospace Company, Kawasaki Heavy Industries, Ltd., Kakamigahara 504-8710, Japan

\begin{abstract}
A post-weld heat treatment process, that is, solution treatment and aging, was found to be effective in improving the fatigue strength of friction stir welded Ti-6Al-4V butt joints. The stir-zone microstructure was changed by friction stir welding, from an equiaxed- $\alpha$ structure to a lamellar structure, but equiaxed- $\alpha$ structure remained in the base metal. Subsequently, solution treatment and aging modified these microstructures to bimodal structures in both the stir zone and base metal. The hardness in the stir zone differed from the base metal after friction stir welding, but the difference was eliminated by solution treatment and aging. The fatigue strength of friction stir welded Ti-6Al-4V butt joints was successfully increased by solution treatment and aging, which was higher than that of the parent Ti-6Al-4V plate. This indicates that solution treatment and aging increases the fatigue strength of friction stir welded Ti-6Al-4V butt joints by the formation of similar bimodal structures in the stir zone and base metal, resulting in reduced stress concentration at these boundaries and retarded fatigue failure.

[doi:10.2320/matertrans.M2017117]
\end{abstract}

(Received April 6, 2017; Accepted May 17, 2017; Published June 30, 2017)

Keywords: titanium alloy, friction stir welding, fatigue

\section{Introduction}

Titanium alloys are utilized in aerospace components with complex shapes; welding these components is particularly effective for cost-reduction by saving the amount of materi$\mathrm{al}^{1)}$. Moreover, welding aids in the repair of small defects or damage that occur during fabrication or actual use ${ }^{2)}$. Therefore, the improvement of the welding techniques and the mechanical properties of the welded components are highly desired in the aerospace industry.

Friction stir welding (FSW) is an attractive process because it is a solid-state joining technique leading to defect-free welds ${ }^{3,4}$. Particularly, fatigue strength is reduced by welding defects such as pores formed in the welded zone of laser-welded $(\alpha+\beta)$-type titanium alloy butt joints ${ }^{5)}$. Therefore, FSW is expected to prevent the deterioration of fatigue strength. However, it has been reported that the fatigue performance of a friction stir welded $(\alpha+\beta)$-type titanium alloy butt joint was lower than that of the parent plate for as-welded and post-weld heat-treated joints ${ }^{6)}$. However, these post-weld heat treatments were performed for stress relief. Therefore, in this study, solution treatment and aging were examined to increase the fatigue strength of friction stir welded Ti-6Al-4V butt joints.

\section{Experimental Procedure}

Commercial 5-mm-thick Ti-6Al-4V alloy plates (denoted as FSW-base) with equiaxed- $\alpha$ structure were cut to

\footnotetext{
${ }^{* 1}$ Corresponding author, E-mail: nakai@mech.kindai.ac.jp

${ }^{* 2}$ Graduate Student, Tohoku University
}

$300 \mathrm{~mm} \times 50 \mathrm{~mm} \times 5 \mathrm{~mm}$ samples. Position-controlled butt-welding was performed at Kawasaki Heavy Industries, Ltd. using a W-La tool with the rotation and welding speeds of $150 \mathrm{rpm}$ and $140 \mathrm{~mm} \cdot \mathrm{min}^{-1}$, respectively (samples denoted as FSW-asweld). After the FSW, the welded joints were solution treated at $1243 \mathrm{~K}$, which is slightly below the $\beta$ / $(\alpha+\beta)$ transformation temperature of Ti-6Al-4V $(\beta$ transus; around $1268 \mathrm{~K}$ ), for $5.4 \mathrm{ks}$, followed by water quenching with aging at $753 \mathrm{~K}$ for $28.8 \mathrm{ks}$, then air cooling (sample denoted as FSW-STA). These heat treatment conditions were determined using the AMS standard (AMS-H-81200).

The microstructures of the cross-sections of the FSW-asweld and FSW-STA were examined using optical microscopy $(\mathrm{OM})$ and scanning electron microscopy equipped with energy-dispersive X-ray analysis (SEM/EDS).

The Vickers hardness values of the FSW-asweld and FSW-STA cross-sections were measured in air at room temperature under a constant load of $9.8 \mathrm{~N}$ for a holding time of $15 \mathrm{~s}$.

Fatigue plate specimens of the FSW-asweld and FSWSTA were prepared perpendicular to the welding direction. In this study, two specimen geometries were employed as shown in Fig. 1: shorter specimens with a gauge portion that contained only the stir zone to evaluate the fatigue strength purely of the stir zone (SZ specimens), and longer specimens with a gauge portion that contained both the stir zone and base metal for evaluating the joint fatigue strength (joint specimens). For comparison, a fatigue plate specimen of the FSW-base with the same geometry as the FSW-asweld and FSW-STA was prepared. The specimen thickness was reduced to $2.5 \mathrm{~mm}$ from $5.0 \mathrm{~mm}$ by grinding by $1.25 \mathrm{~mm}$ from both sides of the joint plates. The fatigue test was conducted 
in air at room temperature using an electric machine with a capacity of $10 \mathrm{kN}$ under a sinusoidal wave with a frequency of $10 \mathrm{~Hz}$ and a stress ratio of $\mathrm{R}=0.1$ in the tension-tension mode.

(a)

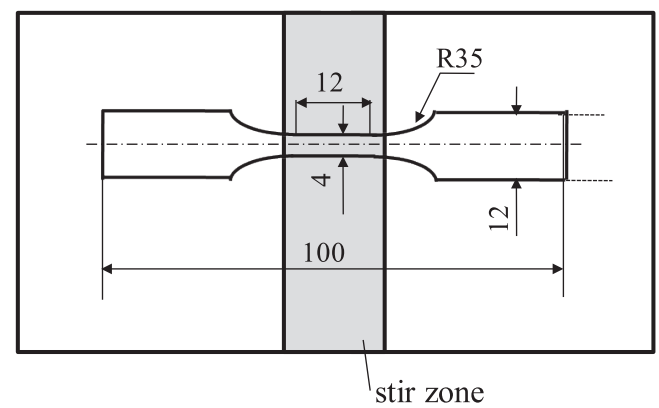

(b)

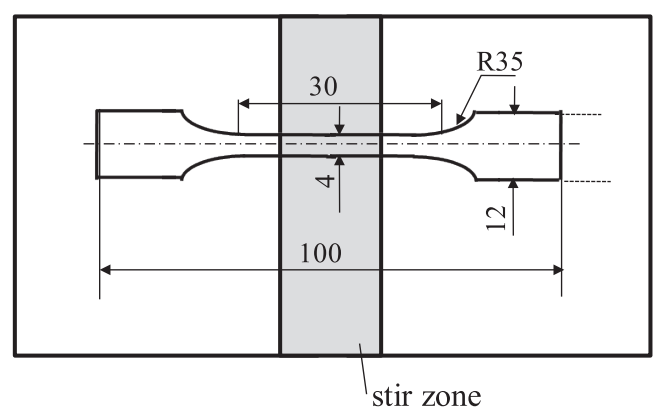

(Unit: $\mathrm{mm}$ )

Fig. 1 Specimen geometries of fatigue tests for FSW-base, FSW-asweld, and FSW-STA: specimens for evaluating fatigue strength of (a) only stir zone (SZ specimen) and (b) complete joint (joint specimen).

\section{Results and Discussion}

Figure 2(a) shows low-magnification SEM images of the FSW-asweld cross-section. White wavy contrast on the advancing side in the stir zone is observed, and the elemental distribution of this white contrast is analyzed using EDS as shown in Fig. 2(b). This contrast is caused by the increased W concentration, deposited from the FSW tool. A similar phenomenon was previously observed when a W-La alloy was used as a tool for the $\mathrm{FSW}^{7)}$.

Figure 3 shows the OM images of the concentrated $\mathrm{W}$ in the stir zone of the FSW-asweld and FSW-STA. While concentrated W is observed clearly in the FSW-asweld, it is noticeably decreased in the FSW-STA. According to the Ti-W binary phase diagram ${ }^{8)}, \mathrm{W}$ is completely miscible within the $\beta$ phase. Therefore, it is presumed that $\mathrm{W}$ probably diffused and dissolved in the stir zone during the solution treatment at $1243 \mathrm{~K}$, resulting in the formation of a dilute solid solution and thus the disappearance of the concentrated $\mathrm{W}$.

Figure 4 shows high-magnification SEM images of the stir zone and base metal for FSW-asweld and FSW-STA. Equiaxed- $\alpha$ structure is observed in the base metal for the FSW-asweld because this region was not heated during the FSW, while lamellar structure is observed in its stir zone. This indicates that the stir zone was heated above $\beta$-transus during FSW. However, similar stir zone and base metal microstructures are observed for the FSW-STA. The microstructure of the FSW-STA stir zone before solution treatment was lamellar. Furthermore, the solution treatment temperature was in the range of the $(\alpha+\beta)$ two-phase region, but near the $\beta$-transus. Therefore, the volume fraction ratio between the $\alpha$ and $\beta$ phases changed. Most of the $\alpha$ lamellae disappeared and became $\beta$ grains, while a few $\alpha$ lamellae and recrystallized grains were coarsened at elevated temperature during the solution treatment. Then the coarsened $\alpha$ phase remained, and secondary $\alpha$ lamellae were precipitated and subsequently grew within the $\beta$ grains during aging,

(a)

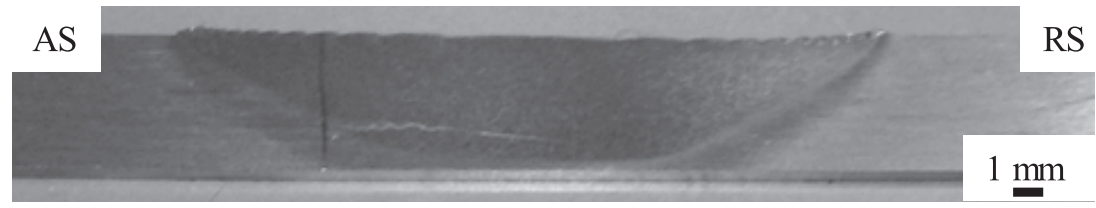

(b)
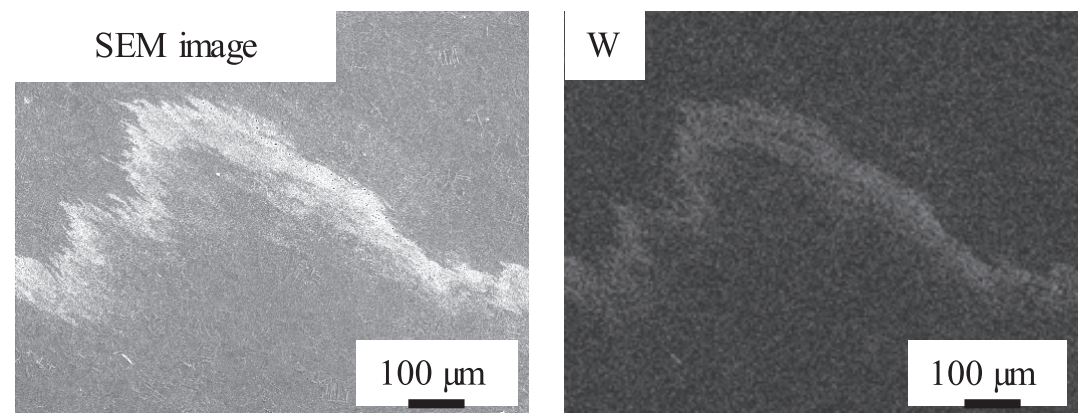

Fig. 2 (a) Macrostructure of FSW-asweld cross-section; (b) SEM image and EDS analysis of white wavy contrast in stir zone shown in (a). 
(a)

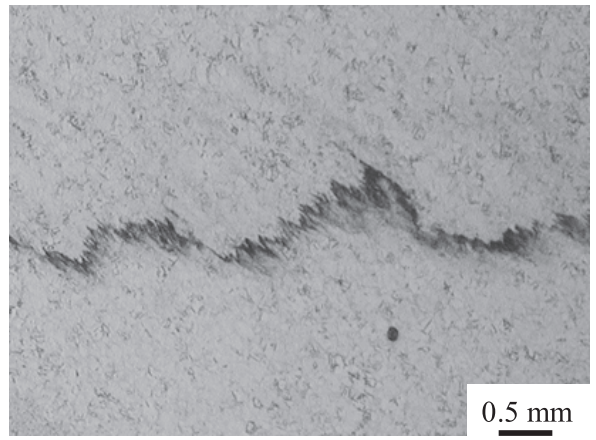

(b)

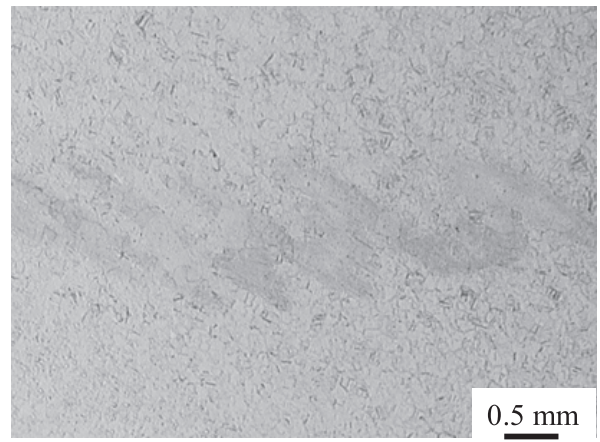

Fig. 3 OM images at positions of concentrated W in stir zone of (a) FSW-asweld and (b) FSW-STA.

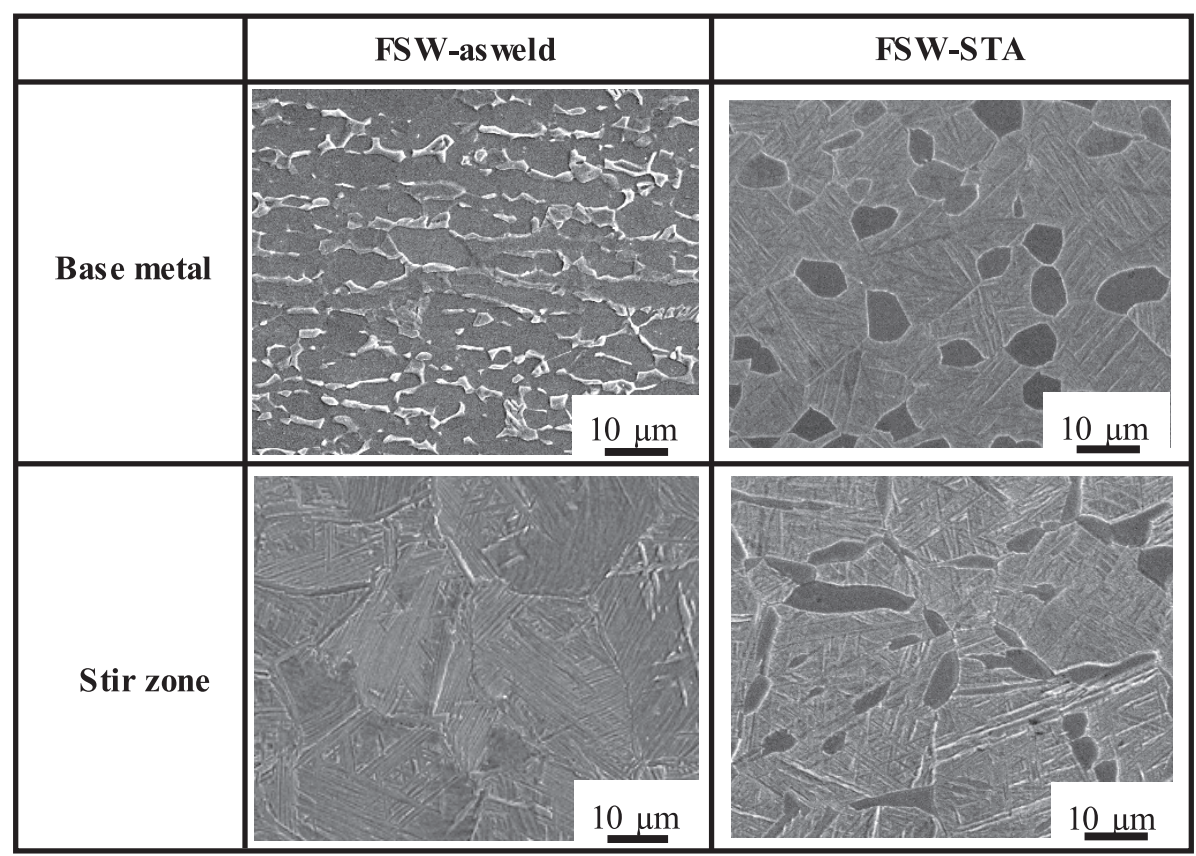

Fig. 4 Microstructures of stir zone and base metal for FSW-asweld and FSW-STA.

resulting in the formation of a bimodal structure. However, the FSW-STA base metal microstructure before the solution treatment was an equiaxed- $\alpha$ structure. Therefore, some equiaxed- $\alpha$ grains remained during the solution treatment, and then the lamellar structure was formed in the other part during aging, resulting in the formation of a bimodal structure. Thus, a bimodal structure was formed in both FSWSTA stir zone and base metal, although the shape of the $\alpha$-phase formed in these two regions was slightly different.

Figure 5 shows the Vickers hardness distributions in the stir zone vicinity for the FSW-asweld and FSW-STA. The hardness values in the stir zone are higher than those in its vicinity for the FSW-asweld, corresponding to the microstructural differences between the stir zone and base metal. On the contrary, for FSW-STA, the microstructure in the stir zone was similar to that in the base metal, resulting in similar hardness values. Moreover, the overall hardness distribution for the FSW-STA is higher than that of the FSW-asweld.

Figure 6 shows the fatigue test results for FSW-base,

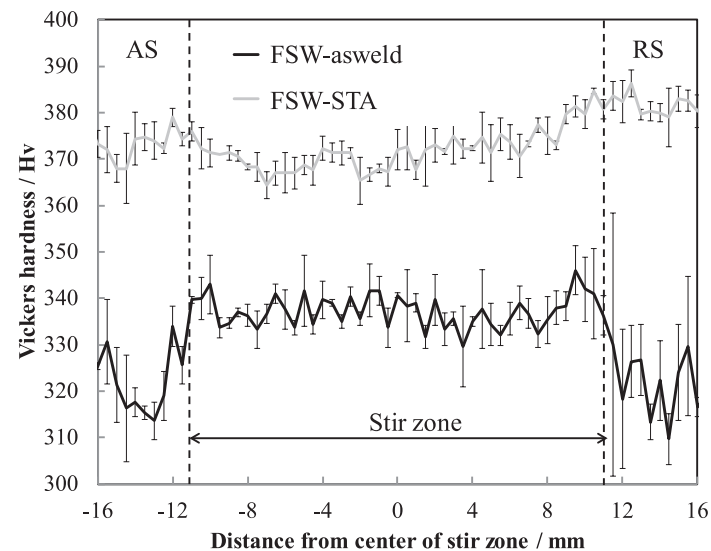

Fig. 5 Vickers hardness distributions in stir zone vicinity for FSW-asweld and FSW-STA.

FSW-asweld, and FSW-STA. The fatigue strengths of both the FSW-asweld and FSW-STA SZ specimens are higher than that of FSW-base. However, the fatigue strength of only 

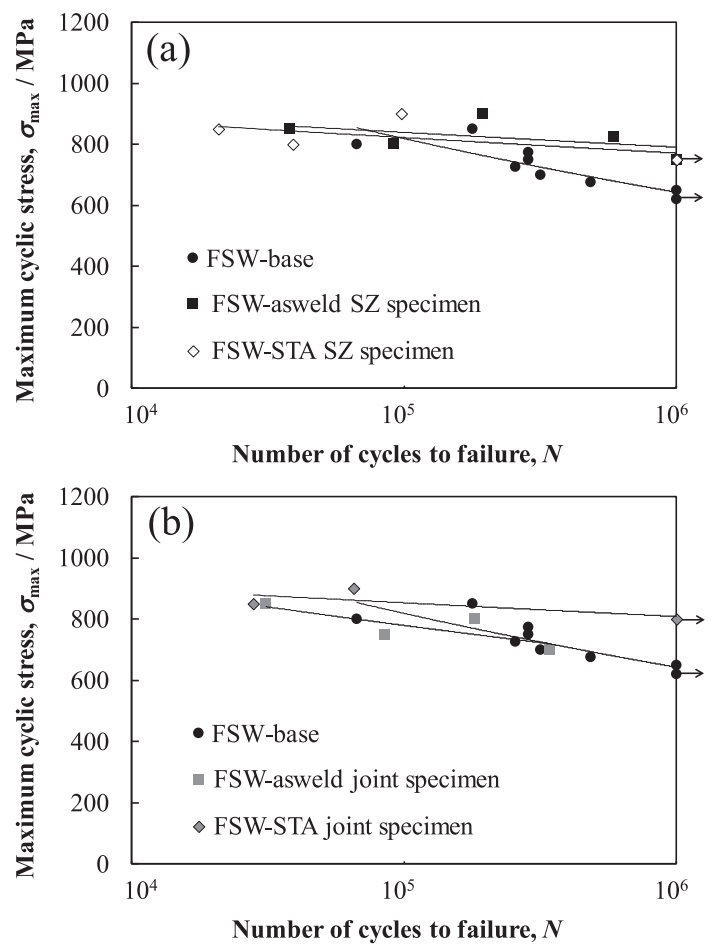

Fig. 6 Results of fatigue tests for FSW-base, FSW-asweld, and FSW-STA using specimens for evaluating fatigue strength of (a) only stir zone (SZ specimen) and (b) complete joint (joint specimen).

the FSW-STA joint specimen is higher than that of FSWbase. Then, the fatigue failure points of the joint specimens were observed, which were different between FSW-asweld and FSW-STA; failure tended to occur in the vicinity of the boundary between the stir zone and base metal in addition to inside the stir zone in the FSW-asweld joint specimens. However, failure occurred inside the stir zone for every FSW-STA joint specimen. The microstructure was observed to drastically change from the stir zone (lamellar structure) to base metal (equiaxed- $\alpha$ structure) for FSW-asweld. Therefore, this inhomogeneous microstructure is likely to induce stress concentration in the stir zone and base metal boundary vicinity in the FSW-asweld joint specimen during the fatigue test. On the contrary, similar bimodal structures exhibiting similar hardness values were observed in the FSW-STA stir zone and base metal. This relatively homogeneous microstructure should have resulted in a more homogeneous stress distribution in the FSW-STA joint specimens. Therefore, the fatigue strength of the FSW-STA joint specimen is similar to that of the corresponding SZ specimen, which is higher than that of FSW-base.

Furthermore, the concentrated $\mathrm{W}$ observed in the stir zone did not affect the fatigue strength because the fatigue failure point was not related to the $\mathrm{W}$-concentration position for the FSW-asweld SZ specimens. W is completely miscible with $\beta$-Ti and no intermetallic compounds are formed in accordance with the Ti-W binary phase diagram ${ }^{8}$. In addition, Choe et al. examined the microstructure and mechanical properties of (Ti-6Al-4V)-10 mass \% W produced by powder metallurgy ${ }^{9)}$. The $\mathrm{W}$ particles were dissolved fully or partially in the Ti-6Al-4V matrix sintered above the $\beta$-transus depending on the $\mathrm{W}$ particle sizes. The ductility was not affected by the $\mathrm{W}$ dissolution for the fully-dissolved samples, while it was deteriorated for the partially-dissolved samples because of brittle failure due to the presence of $\mathrm{W}$ particles. In this study, the samples were heated above $\beta$ transus during the FSW, and the concentrated W was not observed on the fracture surface after fatigue test. Therefore, the concentrated $\mathrm{W}$ in the stir zone probably existed as a solute in solid solution, resulting in no detrimental effects on the fatigue strength of FSW-asweld SZ specimens.

\section{Conclusion}

Solution treatment and aging were carried out as a postweld heat treatment to increase the fatigue strength of friction stir welded butt joints of 5-mm-thick equiaxed- $\alpha$ structure Ti-6Al-4V plate. The microstructure and fatigue strength of butt joints and a specimen cut from only the stir zone were evaluated. The microstructure changed from equiaxed- $\alpha$ structure to lamellar structure in the FSW-asweld stir zone, and then changed from lamellar and equiaxed- $\alpha$ structures in the stir zone and base metal, respectively, to bimodal structures after solution treatment and aging. Corresponding to the microstructure, the hardness was unchanged when comparing the stir zone and base metal for FSW-STA, while the hardness of the stir zone was different from that of the base metal for FSW-asweld. The fatigue strength of the FSW-STA butt joint, which was comparable to that of the specimen including only the stir zone for FSW-STA, was higher than that of the parent Ti-6Al-4V plate. This indicates that the bimodal structure formation and the microstructure homogeneity between the stir zone and base metal contributed to increasing the joint fatigue strength. Therefore, although conventional welded joints are usually subjected to stress relief treatment after welding, solution treatment and aging are preferable as a post-weld heat treatment for friction stir welded Ti-6Al-4V butt joint.

\section{Acknowledgments}

This work was supported partly by the project "Advanced Materials \& Process Development for Next-Generation Aircraft Structures" under a contract with SOKEIZAI Center, founded by the Ministry of Economy, Trade and Industry (METI), Japan.

\section{REFERENCES}

1) R.R. Boyer: JOM 62 (2010) 21-24.

2) S. Nishikiori: JJILM 55 (2005) 557-560.

3) Y. Zhang, Y.S. Sato, H. Kokawa, S.H.C. Park and S. Hirano: Mater. Sci. Eng. A 485 (2008) 448-455.

4) K. Kitamura, H. Fujii, Y. Iwata, Y.S. Sun and Y. Morisada: Mater. Des. 46 (2013) 348-354.

5) M. Nakai, M. Niinomi, T. Akahori, K. Hayashi, Y. Itsumi, S. Murakami, H. Oyama and W. Abe: Mater. Sci. Eng. A 550 (2012) 55-65.

6) P. Edwards and M. Ramulu: Int. J. Fatigue 75 (2015) 19-27.

7) A.L. Pilchak, W. Tang, H. Sahiner, A.P. Reynolds and J.C. Williams: Metall. Mater. Trans., A 42A (2011) 745-762.

8) T. B. Massalski, H. Okamoto, P. R. Subramanian and L. Kacprzak: Bi nary Alloy Phase Diagrams 2nd Edition, (ASM International, Materials Park, OH, USA, 1990) pp.

9) H. Choe, S.A. Abkowitz, S. Abkowitz and D.C. Dunand: Mater. Sci. Eng. A 396 (2005) 99-106. 